\title{
Glutamate Decarboxylase-, Insulin-, and Islet Cell-Antibodies and HLA Typing to Detect Diabetes in a General Population-based Study of Swedish Children
}

\author{
William A. Hagopian, * Carani B. Sanjeevi, ${ }^{\ddagger}$ Ingrid Kockum, ${ }^{\ddagger}$ Mona Landin-Olsson, ${ }^{5}$ Allan E. Karlsen, " Göran Sundkvist," \\ Gisela Dahlquist, ${ }^{\star \star}$ Jerry Palmer, ${ }^{\star}$ and Åke Lernmark ${ }^{\star *}$ \\ * Department of Medicine, University of Washington, Seattle, Washington 98195; ${ }^{\ddagger}$ Department of Molecular Medicine, Karolinska \\ Institute, S 17676 Stockholm, Sweden; ${ }^{\S}$ Department of Medicine, University of Lund, University Hospital, S 22185 Lund, Sweden; \\ "Steno Diabetes Center, DK 2820 Gentofte, Denmark; 'Department of Medicine, University of Lund, Malmö General Hospital, \\ S 21461 Malmö, Sweden; and **Department of Pediatrics, Umeå University, S 90185 Umeå, Sweden
}

\begin{abstract}
Most autoimmune diabetes occurs in those without a diabetic relative, but few cases are identifiable prospectively. To model general population prediction, 491 consecutive newly diabetic children from all of Sweden were tested for autoantibodies to glutamate decarboxylase (GAD65ab), insulin (IAA), and islet cells (ICA), and for HLA-DQ genotypes by PCR; 415 matched control children were tésted in parallel. GAD65ab sensitivity/specificity was 70/96\%, versus $84 / 96 \%$ for ICA, $56 / 97 \%$ for IAA, $93 / 93 \%$ (any positive), 39/99.7\% (all positive), and 41/99.7\% (GAD65ab plus IAA). The latter's $25 \%$ predictive value was not improved by requiring concomitant high-risk HLA genotypes. GAD65ab were associated with DQA1*0501/B1*0201 (DQ2; $P=0.007)$ but not DQA1 *0301/B1 *0302 (DQ8), and IAA with DQA1*0301/B1 *0302 (DQ8; $P=0.03)$ but not DQA1*0501/B1*0201 (DQ2). GAD65ab were more prevalent in females than males $(79$ vs. $63 \% ; P<0.0001)$ but did not vary with onset age nor season. Combining the three antibody assays yielded sufficient sensitivity for screening. GADab were relatively sensitive/specific for diabetes, but even with HLA marker combinations yielded predictive values insufficient for early immunointervention in the low-prevalence general population. (J. Clin. Invest. 1995. 95:1505-1511.) Key words: autoimmunity - prediction • IAA • GAD • insulin-dependent diabetes
\end{abstract}

\section{Introduction}

Autoantibody tests, along with genetic typing, $\beta$ cell function testing, and perhaps tests of $\mathrm{T}$ lymphocyte function, may reveal autoimmune insulin-dependent diabetes mellitus (IDDM) ${ }^{1}$ be-

This work was presented in abstract form at the 53rd Annual Meeting of the American Diabetes Association, Las Vegas, NV, 1993.

Address correspondence to William Hagopian, M.D. Ph.D., Department of Medicine, RG-20, University of Washington, Seattle, WA 98195. Phone: 206-543-5316; FAX: 206-543-3169.

Received for publication 20 September 1994 and in revised form 9 December 1994.

1. Abbreviations used in this paper: DQ2, HLA DQA1*0501/ DQB1 *0201; DQ8, HLA DQA1 *0301/DQB1 *0302; GAD, glutamate decarboxylase; GAD65ab, 65-kD glutamate decarboxylase autoantibodies; IAA, competitive insulin autoantibodies; ICA, islet cell antibodies IDDM, insulin-dependent diabetes mellitus; PPV, positive predictive value.

J. Clin. Invest.

(c) The American Society for Clinical Investigation, Inc.

0021-9738/95/04/1505/07 \$2.00

Volume 95, April 1995, 1505-1511 fore clinical onset. Through such prediction, we may $(a)$ study early disease pathogenesis in humans, $(b)$ screen large populations to intervene years before clinical onset, and $(c)$ test lowtoxicity immunointervention strategies.

Current studies require $\beta$ cell function below the first percentile to achieve sufficient predictive value for intervention, but prediction earlier in the pathogenesis has many theoretical advantages. More $\beta$ cells remain, so the secretory load per cell is not excessive (1) lessening $\beta$ cell antigen expression (2) and probably susceptibility to autoimmune killing. Less clonal expansion of autoaggressive cells has occurred, and more noninfiltrated islets remain (3). Fewer antigens are autoimmune targets (4) so low-toxicity therapies interrupting single antigen responses may be effective.

Most new IDDM occurs in persons without a diabetic relative (5) and peak incidence is at puberty, so studies screening healthy schoolchildren are ideal. However, large studies testing for example 4,000 healthy children, yield only a few prediabetic subjects per year $(6,7)$. This is clearly inadequate for testing predictive strategies or immunointervention. Testing relatives of IDDM patients is rewarding because greater disease prevalence allows identification of $20-30$ prediabetics in the largest studies (8). Following them to clinical onset allows study of pathophysiology and marker prevalence during the preclinical phase. However, even dozens of prediabetics is insufficient to study complex combinations of several markers, each positive in only some cases. Also, there is no guarantee that familial and sporadic IDDM have the same marker prevalences.

Given the prolonged course of IDDM, and the fact that 5$10 \%$ of the $\beta$ cells still remain to be destroyed at clinical onset, children with new-onset IDDM are a reasonable model of prediabetes. In fact, numerous studies of glutamate decarboxylase (GAD) (64 kD) antibodies (9), competitive insulin autoantibodies (IAA) (10), and islet cell antibodies (ICA) (11) all suggest that for most patients, autoantibodies at onset correlate to those present much earlier. Therefore, we tested 491 children with new-onset IDDM and 415 healthy control children carefully matched by age, sex, and geography. Subjects were recruited in a population-based manner from all of Sweden. Most came from families without a history of IDDM. This crosssectional population-based study achieved high ascertainment and avoided recruitment bias (6). We sought to test if prediction is improved by adding $65-\mathrm{kD}$ glutamate decarboxylase autoantibodies (GAD65ab) and HLA genotyping to ICA and IAA already described in these children (6) and to find combinations useful for detecting childhood diabetes.

\section{Methods}

Patient population. The Swedish Childhood Diabetes Register (5) ascertains $99 \%$ of Swedish children aged 0-14.9 yr developing IDDM. 
Blood samples were obtained from 494 of 515 consecutive newly diagnosed cases (96\%) registered from September 1986 through December 1987. Median patient age was $9 \mathrm{yr}$ and the male/female ratio was 1.08 . The control group was from two sources. For ethical reasons, control children below age 7 ( $n=52,12 \%$ of controls) were included when blood was already being obtained for a non-endocrine and non-infectious medical indication. The remainder of controls $(n=371,88 \%$ of controls) were children aged 7-14 yr selected from the general population as described $(6,12)$. For each case, two controls were identified from the Swedish Population Register who were of the same gender, birth date, and county of birth. The controls and their families were told that the study was a health survey without specific mention of diabetes to avoid selection bias, and $371 / 718$ controls ( $52 \%$ ) chose to participate Control samples were received an average of 6 weeks after onset in the referent case. Questionnaires received from $416 / 515$ patients and $350 /$ 423 controls revealed a family history positive for IDDM in $43 / 416$ (10.3\%) of cases and $8 / 350(2.3 \%)$ of controls. During 3-5 years of follow-up, both the childhood and adult diabetes registers were checked for controls who were newly registered as diabetics. Three of 423 controls with pre-existing or subsequent diabetes were excluded from analysis. Informed consent was obtained from all parents and children. The study was approved by the Swedish Data Inspection Board and by the Ethical Committee, Karolinska Institute, Stockholm.

Islet cell and insulin autoantibodies. Venous blood was collected into EDTA tubes. Plasma, and genomic DNA isolated from peripheral blood leukocytes, were each stored at $-80^{\circ} \mathrm{C}$ until analysis. Islet cell cytoplasmic antibodies (ICA) were measured by indirect two-color immunofluorescence using blood group $\mathrm{O}$ frozen human pancreas as described (13). One pancreas was used throughout the study. Coded slides were evaluated by two independent observers. Each assay included internal standards. Samples were titrated in doubling dilutions to determine endpoint titer for conversion to Juvenile Diabetes Foundation Units (JDFU) by comparison with an international reference serum as described (6). Assay standard deviation was 1.0 titration steps, corresponding to a coefficient of variation of $15 \%$. The lower limit of detection was $3 \mathrm{JDFU}$. The laboratory participates in ICA proficiency workshops. Competitive insulin autoantibodies (IAA) were measured by radiobinding assay using acid-charcoal extraction and cold insulin displacement $(\Delta \%)$ as described (14) in a laboratory participating in proficiency workshops. In 414/494 patients, blood was obtained within $10 \mathrm{~d}$ of the first insulin injection, which should avoid antibodies to exogenous insulin. IAA were measured in $392 / 414$ of these. The cutoff for positive samples was $0.79 \%$, defined as the 99th percentile among 420 nondiabetic controls.

HLA typing. A total of 425 cases and 367 controls were typed for HLA DQ using polymerase chain reaction combined with sequencespecific oligonucleotide probes (15) and by restriction fragment length polymorphism using DR- and DQ-based probes to confirm haplotypes (16)

GAD65 antibodies. Details of the immunoprecipitation assay have been described (17). Briefly, a hamster fibroblast line transfected with cDNA representing human islet 65-kD GAD (GAD65) was biosynthetically labeled with $\left[{ }^{35} \mathrm{~S}\right]$ methionine $\left(1 \mathrm{mCi} / 10^{7}\right.$ cells; Amersham, $\mathrm{Ar}$ lington, IL). The membrane detergent fraction (18) containing most cellular GAD65 (19) was precleared with normal human serum not subsequently used in the assay. About $5 \times 10^{5} \mathrm{cpm}$ of extract was incubated with each $10 \mu \mathrm{l}$ plasma sample at a dilution of $1: 60$ for $16 \mathrm{~h}$ at $4^{\circ} \mathrm{C}$. Immune complexes were precipitated with Protein A-Sepharose (PAS) (Zymed, South San Francisco, CA) and electrophoresed on polyacrylamide gels. Fluorograms each included positive and negative control human sera, and a positive control GAD monoclonal antibody. Visible bands at $64 \mathrm{kD}$ were quantified by laser densitometry $(2202$ Ultroscan, LKB, Sweden). GAD65ab index was calculated from integrated peak areas as described (17). Intra-assay and inter-assay coefficients of variation were 26 and $29 \%$, respectively. This assay achieved $100 \%$ sensitivity and $100 \%$ specificity in the first GAD Antibody Workshop (20).

Statistical analyses. Values are given as mean, range, and standard deviation if normally distributed, otherwise as mean, median, range, and quartile distribution. Differences in antibody levels were tested by the Mann-Whitney U test. Correlations between various antibody levels and between antibody level and age were tested by Spearman rank correlation $\left(r_{\mathrm{s}}\right)$. Two-tailed probability of $P=0.05$ was considered significant. Associations between antibodies and HLA types and between family history and markers were tested using Chi square unless any expected value was $<5$, when Fisher's exact test was substituted. Fischer's exact test was used for HLA disease associations, and $p$ values were corrected for the total number of comparisons made $(n=\dot{8}$ for $\mathrm{DQ} \alpha$ and $n=13$ for $\mathrm{DQ} \beta$ ). Positive predictive values (PPV) were calculated as: $\mathrm{PPV}=(\mathrm{P} \times \alpha) /\{(\mathrm{Pxa})+[(1-\mathrm{P}) \times(1-\beta)]\}$ where $\alpha=$ sensitivity, $\beta=$ specificity, and $\mathrm{P}=$ prevalence. Sensitivity was defined as (cases testing positive/ total cases tested), and specificity as $\{1$-(controls testing positive/total controls tested) $\}$. Prevalence $(P)$ was estimated at $0.208 \%$ from the formula $P=$ (incidence $\times$ mean duration) using the measured incidence of $26 / 100,000$ for $0-15$ yr olds in Sweden in 1986-1987 and a mean duration of $8 \mathrm{yr}$ (21). Confidence intervals for all PPV were calculated by applying confidence intervals for proportions to test specificities.

\section{Results}

Association of GAD65ab with diabetes. GAD65ab were detected in $343 / 488$ diabetic children $(70.3 \%)$ and $17 / 412$ matched controls $(4.1 \%)(P<0.0001)$. This compares with $415 / 495(83.8 \%)$ cases and $17 / 417(4.1 \%)$ controls with ICA, and $219 / 392(55.9 \%)$ cases and $11 / 392(2.8 \%)$ controls with IAA (Table 1A), as previously reported (6). Quantitative GAD65ab indices (17) for diabetics and controls are plotted in Fig. $1 \mathrm{~A}$. In GAD65ab-positive cases, mean GAD65ab index was 0.77 , median 0.20 , and range $0-7.92$. For controls, mean GAD65ab index was 0.20 , median 0.04 , and range $0-1.62$, with mean lower than cases $(P=0.048)$. GAD65ab index was not normally distributed in cases nor controls. Quartile distributions were $0.07,0.20,1.06$, and 7.92 in 343 patients, and 0.03, 0.07, 0.17 , and 1.62 in 17 controls.

GAD65ab prevalence versus age, gender, and season of onset. Unlike IAA (22) no significant association of GAD65ab prevalence or index with onset age was found in the $0-15$ year age range $\left(r_{\mathrm{s}}, P=0.82\right)$. Prevalence in females $(79 \%)$ was higher than in males $(63 \%)(P<0.0001)$, an effect seen in children of all ages within the study range (Fig. $1 B$ ). An association between season and IDDM incidence is well known (23), but no association was found between GAD65ab prevalence or index and season of onset.

Association of HLA with diabetes. Analysis of HLA DQ $\beta$ alleles revealed significant positive association between IDDM and each of DQA $1 * 0301$, DQA $1 * 0501, \mathrm{DQB} 1 * 0201$, and DQB1 *0302. Odds ratios $(95 \% \mathrm{CI})$ were $5.8(4.25-7.89), 2.1$ (1.59-2.83), $3.0(2.20-3.95)$, and 8.1 (5.95-10.95), respectively (all $P<0.001$ ). Negative associations were strongest with DQB $1 * 0503$ and DQB $1 * 0602$, with OR (95\% CI) of $0.04(0.01-0.16)$ and $0.01(0.01-0.04)$, respectively (both $P$ $<0.005)$. Specificity of single high risk alleles for disease, however, was never over 75\%. Requiring both DQB *0201 and DQB *0302 achieved $96.4 \%$ specificity but only $39 \%$ sensitivity. Haplotypes most associated with disease were DQA1* 0301/DQB $1 * 0302$ (cis), DQA $1 * 0501 / \mathrm{DQB} 1 * 0201$ (cis), DQA $1 * 0301 / \mathrm{DQB} 1 * 0201$ (trans), and DQA $1 * 0501 /$ DQB1 *0302 (trans) with odds ratios $(95 \% \mathrm{CI})$ of 8.1 (5.95$10.96), 3.8$ (2.76-5.10), 8.7 (5.88-12.73), and 11.6 (7.4518.03 ), respectively (all $P<0.001$ ). All the above and additional haplotype, single allele, or multiple allele combinations were analyzed for sensitivity and specificity. The best are pre- 

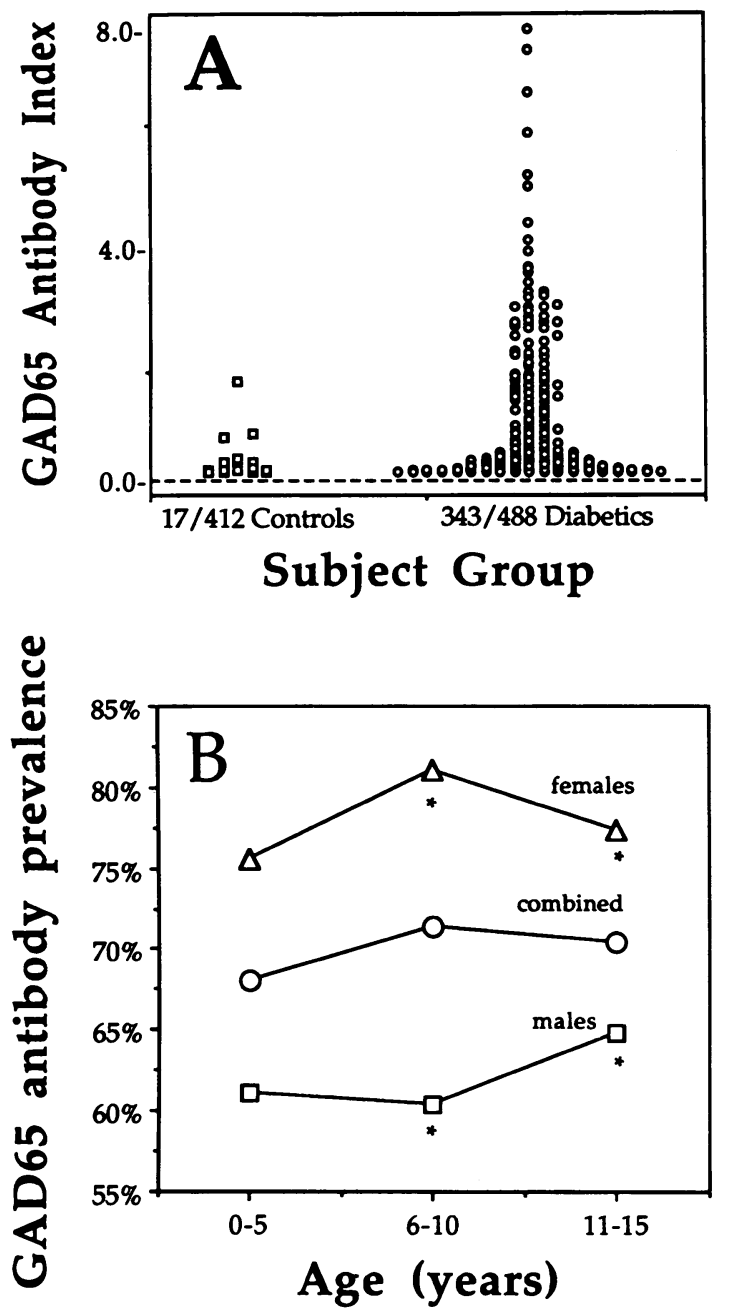

Figure 1. (A) GAD65ab index in 343/488 diabetics with GAD65ab (right), and in 17/412 control children with GAD65ab (left). (B) GAD65ab prevalence versus age and gender in diabetic children. $(\triangle)$ females, ( $\square$ ) males. For the entire cohort, $P<0.0001$ for GAD65ab versus gender. For specific age groups, ${ }^{*} P \leq 0.05$.

sented in Table I $B$. All showed increased specificity only at the cost of low sensitivity (Fig 3, $A$ and $B$; squares). None was useful for screening or intervention. All had PPV $<3 \%$.

Association of HLA with GAD65ab, IAA, and ICA. Probability values for significant association of GAD65ab, IAA and ICA with DQ alleles, haplotypes, and genotypes are summarized in Table II. For subjects with IDDM, GAD65ab were significantly associated with separate DQA $1 * 0501$ and $\mathrm{B} 1 * 0201$ alleles and with the DQA1*0501/B1*0201 (DQ2) haplotype. GAD65ab were not associated with DQA1 *0301/B1 *0302 (DQ8) haplotype or alleles unless present in combination with a DQ2 allele. In the absence of DQ2, DQ8 was negatively associated with GAD65ab. Conversely, IAA were significantly associated with DQA $1 * 0301 / \mathrm{B} 1 * 0302$ (DQ8) alleles and haplotype. In the absence of DQ8, IAA were negatively associated with DQ2. ICA were significantly associated only with the DQA $1 * 0301$ allele found in DQ8, and some DQ7, DQ9, and DQ4 haplotypes. ICA, like IAA but unlike GAD65ab, were negatively associated with DQ2 in the absence of DQ8. It was not possible to test these associations in the absence of diabetes, due to the small number of the 324 DQ-typed control children with autoantibodies (Table I $A$ ).

Association of autoantibody and HLA markers with family history of IDDM. Although family history of IDDM is associated with an increased risk of disease (5), only $10.3 \%$ of cases had such a history, with an overall predictive value of only $0.9 \%$. Comparison of marker positivity between the 43 cases with a family history of IDDM and the 368 cases without such a history, showed no significant difference for any autoantibody test, HLA test, or any test combination (data not shown). A significantly higher prevalence of high risk HLA DQ types was found in the eight control subjects with a family history of IDDM versus those without such a history, but none of the control subjects with such a family history had autoantibodies.

Relationship between the three autoantibody tests. Similar to previous, smaller studies $(17,24,25)$ GAD65ab index in the 491 cases was significantly correlated with ICA titer $(P$ $<0.001)$, but not with IAA $\Delta \%(P=0.19)$. IAA $\Delta \%$ and ICA titers also were not correlated $(P=0.48)$. Too few subjects had autoantibodies to test correlations in the control group.

Importantly, 40/488 (8.2\%) patients had GAD65ab without detectable ICA. In patients with negative ICA and weak GAD65ab, the recombinant assay may be more sensitive for GAD65ab than the ICA assay. However, 15 patients with negative ICA had higher GAD65ab levels (index >0.13), suggesting some GAD epitopes may not be preserved in the ICA assay format. Conversely, 105/488 (21.5\%) had ICA without GAD65ab, and 46 of these also were IAA-negative, consistent with ICA assay detection of islet antigen(s) distinct from insulin and GAD $(26,27)$.

Combining autoantibody tests to predict IDDM. The relationship between number of positive autoantibody tests (each of ICA, IAA, and GAD65ab) and diabetes is shown in Fig. 2. Only 33/392 control children were positive for even one test, while $298 / 386$ patients were positive in at least two tests. Sensitivity/specificity of positivity in one, two, or three tests were $93 / 93 \%, 75 / 98.5 \%$, and $39 / 99.7 \%$, respectively. The latter had predictive value of $24 \%$.

ICA, IAA, and GAD65ab analyzed in various combinations to determine disease association are shown in Table I $A$. Only the "GAD65ab or ICA or IAA" test was over $90 \%$ sensitive (potentially useful for screening) while "GAD65ab and IAA" was $99.75 \%$ specific. The latter could be useful for low-toxicity intervention, since a specificity of $99.75 \%$, with $90 \%$ sensitivity and $0.2 \%$ prevalence, achieves $50 \%$ predictive value. However, all highly specific combinations were insensitive, so the highest predictive value for any test combination was only $25 \%$. This important "tradeoff" between sensitivity and specificity limited predictive values, especially for higher sensitivity test combinations. It is best shown graphically in Fig. 3, $A$ and $B$.

Combining HLA and antibody markers to predict IDDM. Combinations of diabetes-associated DQ alleles, ranging from high sensitivity/low specificity to high specificity/low sensitivity (Table I $B$ ), were combined with antibody tests (Table I $A$ ) for overall sensitivity, specificity and predictive value. The three most sensitive/specific HLA combinations combined with the four most sensitive/specific antibody combinations are shown in Table I $C$. Adding these HLA markers to antibody test results increased specificity only at the cost of lowered sensitivity. Predictive values were not improved (Fig. 3, $A$ and $B$; open circles). Although not shown in Table I, the 25\% PPV of the IAA and GAD65ab combination was also not improved, since 


\begin{tabular}{|c|c|c|c|c|c|c|c|c|c|}
\hline & \multicolumn{3}{|c|}{ IDDM patients } & \multicolumn{3}{|c|}{ Matched controls } & \multicolumn{3}{|c|}{ Predictive value } \\
\hline & Pos & Total & Percent $=$ sens & Pos & Total & Percent & $1-$ percent $=$ spec & PPV & $95 \% \mathrm{CI}$ \\
\hline \multicolumn{10}{|l|}{ A. Autoantibody tests } \\
\hline GADab & 343 & 488 & 70 & 17 & 412 & 4.1 & 95.9 & 3.4 & $2.4-6.2$ \\
\hline ICA & 415 & 495 & 84 & 17 & 417 & 4.1 & 95.9 & 4.1 & $2.8-7.4$ \\
\hline IAA & 219 & 392 & 56 & 11 & 392 & 2.8 & 97.2 & 4.0 & $2.6-9.0$ \\
\hline GADab, ICA, or IAA (any positive) & 357 & 385 & 93 & 27 & 392 & 6.9 & 93.1 & 2.7 & $2.0-4.2$ \\
\hline GADab and IAA & 158 & 385 & 41 & 1 & 392 & 0.3 & 99.7 & 25 & $10-100$ \\
\hline GADab and ICA & 303 & 488 & 62 & 4 & 412 & 1.0 & 99.0 & 12 & $6-100$ \\
\hline ICA and IAA & 186 & 392 & 47 & 3 & 392 & 0.8 & 99.2 & 11 & $6-100$ \\
\hline Any $2 \mathrm{ab}$ positive & 290 & 385 & 75 & 6 & 392 & 1.5 & 98.5 & 9.3 & $5.4-33$ \\
\hline GADab, ICA, and IAA (all positive) & 151 & 385 & 39 & 1 & 392 & 0.3 & 99.7 & 24 & $10-100$ \\
\hline \multicolumn{10}{|l|}{ B. HLA DQ genotypes } \\
\hline not B0602 (1) & 426 & 429 & 99 & 273 & 364 & 75.0 & 25.0 & 0.3 & $0.3-0.3$ \\
\hline $\mathrm{A} 0301$ or $\mathrm{A} 0501$ & 408 & 429 & 95 & 252 & 364 & 69.2 & 30.8 & 0.3 & $0.3-0.3$ \\
\hline B0302 or B0201 not B0602 & 390 & 429 & 91 & 172 & 364 & 47.3 & 52.7 & 0.4 & $0.4-0.4$ \\
\hline A0301 not B0602 & 344 & 429 & 80 & 133 & 364 & 36.5 & 63.5 & 0.5 & $0.4-0.5$ \\
\hline B0302 & 315 & 429 & 73 & 101 & 364 & 27.7 & 72.3 & 0.5 & $0.5-0.7$ \\
\hline B0302 not B301,303,503,602, or $603(2)$ & 281 & 429 & 66 & 43 & 364 & 11.8 & 88.2 & 1.1 & $0.9-1.6$ \\
\hline A0301/B0201 trans & 180 & 429 & 42 & 29 & 364 & 8.0 & 92.0 & 1.1 & $0.8-1.7$ \\
\hline B0201 and B0302 (3) & 166 & 429 & 39 & 13 & 364 & 3.6 & 96.4 & 2.2 & $1.5-4.6$ \\
\hline \multicolumn{10}{|l|}{ C. Combined ab + HLA tests } \\
\hline GADab or ICA or IAA, and HLA (1) & 323 & 343 & 94 & 26 & 348 & 7.5 & 92.5 & 2.6 & $1.9-4.0$ \\
\hline GADab and HLA (1) & 300 & 424 & 71 & 13 & 364 & 3.6 & 96.4 & 4.0 & $2.6-8.1$ \\
\hline ICA and HLA (1) & 359 & 427 & 84 & 11 & 364 & 3.0 & 97.0 & 5.5 & $3.5-12$ \\
\hline any 2 ab positive, and HLA (1) & 264 & 343 & 77 & 6 & 348 & 1.7 & 98.3 & 8.5 & $4.9-31$ \\
\hline GADab or ICA or IAA, and HLA (2) & 226 & 343 & 66 & 5 & 348 & 1.4 & 98.6 & 8.7 & $4.9-42$ \\
\hline GADab and HLA (2) & 202 & 424 & 48 & 2 & 364 & 0.5 & 99.5 & 15 & $7-100$ \\
\hline ICA and HLA (2) & 243 & 427 & 57 & 2 & 364 & 0.5 & 99.5 & 18 & $8-100$ \\
\hline Any 2 ab positive, and HLA ( 2 ) & 186 & 343 & 54 & 2 & 348 & 0.6 & 99.4 & 16 & $8-100$ \\
\hline GADab or ICA or IAA, and HLA (3) & 137 & 343 & 40 & 3 & 348 & 0.9 & 99.1 & 8.8 & $4-100$ \\
\hline GADab and HLA (3) & 128 & 424 & 30 & 1 & 364 & 0.3 & 99.7 & 19 & $7-100$ \\
\hline ICA and HLA (3) & 143 & 427 & 33 & 1 & 364 & 0.3 & 99.7 & 20 & $8-100$ \\
\hline Any 2 ab positive, and HLA (3) & 116 & 343 & 34 & 1 & 348 & 0.3 & 99.7 & 20 & $8-100$ \\
\hline
\end{tabular}

the one control subject with both autoantibodies was also DQA1 *0501/DQB1 *0201.

\section{Discussion}

The rarity of serum collected from prediabetics in the general population makes evaluation of predictive markers difficult. Since antibodies at onset are generally representative of those in prediabetes (9-11), we analyzed 491 new-onset diabetic cases representing virtually all new childhood diabetes in all of Sweden for 16 mo. To our knowledge this is the largest population-based study of its kind. Most cases occurred in subjects without a family history of diabetes (5).

Sensitive and highly specific tests are critical to prediction in low-prevalence populations. The 492 cases included here allow very accurate measurement of sensitivity. However, specificity is best determined by testing low prevalence groups where most will never get diabetes (28) such as the 415 control children described above. Test specificity determined from these controls has a much greater impact on predictive value than does sensitivity revealed by cases. The control children were well matched to cases by age, gender, and geography, and were recruited in a nonbiased fashion (6). This careful design resulted in recruitment of only 415 of a possible 794 control children, leading to wide $95 \%$ confidence intervals as shown in Table I. While this is an important theoretical limitation, in reality we tested a large number of controls given the difficulties of blood sampling of healthy children.

The current study is cross-sectional, and the predictive values calculated here represent predictive value for detecting newonset diabetes. We assume that autoantibodies present at onset also mark the prediabetic period, so our calculations represent "maximum" prospective predictive value. The true prospective predictive value of these tests must, of course, be confirmed by prospective studies. While we used the estimated population prevalence of diabetes for predictive value calculations, cumulative incidence would be appropriate in studies with prospective follow-up. Since most diabetes under $35 \mathrm{yr}$ of age is autoimmune, it will also be important to validate marker prediction in the 15-35-yr age group.

The classic ICA test (29) using cryosectioned human pancreas is attractive since antibodies to multiple $\beta$ cell components are detected simultaneously. However, antibody tests using distinct recombinant antigens are independent of each other as determined by correlation. This independence is likely the rea- 
Table II. Associations of HLA DQ Genotypes to Autoantibodies in Swedish Diabetic Children

\begin{tabular}{lrrr}
\hline \multicolumn{1}{c}{ HLA type } & GAD65ab & \multicolumn{1}{c}{ IAA } & \multicolumn{1}{c}{ ICA } \\
\hline A0301 & 0.500 & ${ }^{*} 0.011$ & $* 0.001$ \\
B0302 & 0.910 & $* 0.034$ & 0.093 \\
A0501 & $* 0.001$ & 0.985 & 0.246 \\
B0201 & $* 0.008$ & 0.914 & 0.213 \\
B0602 & 0.203 & 0.232 & 0.400 \\
B0503 & 0.709 & 0.557 & 0.844 \\
any DQB Asp 57 & 0.300 & 0.740 & 0.560 \\
A0301 B0302 (DQ8) & 0.910 & $* 0.034$ & 0.093 \\
A0501 B0201 (DQ2) & $* 0.003$ & 0.769 & 0.422 \\
A0301 and B0201 & $* 0.002$ & $* 0.049$ & 0.204 \\
A0501 and B0302 & $* 0.007$ & 0.094 & 0.343 \\
Both DQ2 and DQ8 & $* 0.040$ & 0.130 & 0.207 \\
Neither DQ2 nor DQ8 & 0.500 & 0.860 & 0.394 \\
DQ8 DQ8 & 0.864 & 0.229 & 0.581 \\
DQ2 DQ2 & 0.599 & 0.376 & 0.234 \\
DQ8 and not DQ2 & $* * 0.008$ & 0.679 & 0.774 \\
DQ2 and not DQ8 & 0.770 & $* * 0.016$ & $* * 0.005$ \\
& & & \\
\hline
\end{tabular}

Tests are Chi Square except when any expected value is $<5$, in which case Fisher's exact test is used. ${ }^{*} P<0.05$ for positive association; ** $P<0.05$ for negative association.

son for the high specificity noted for a double positive result (99.75\% for IAA and GAD65ab). Antigens other than insulin and GAD are autoantibody targets, and several have been sequenced $(26,27)$ although not tested here. Combining subjects positive to any two or more of many recombinant antigens may preserve high specificity while increasing sensitivity beyond the $41 \%$ reported here for GAD65ab and IAA.

Recombinant assays have further advantages. ICA are technically difficult to standardize, even after extensive workshops (30). Scale-up to tens of thousands of tests is difficult due to

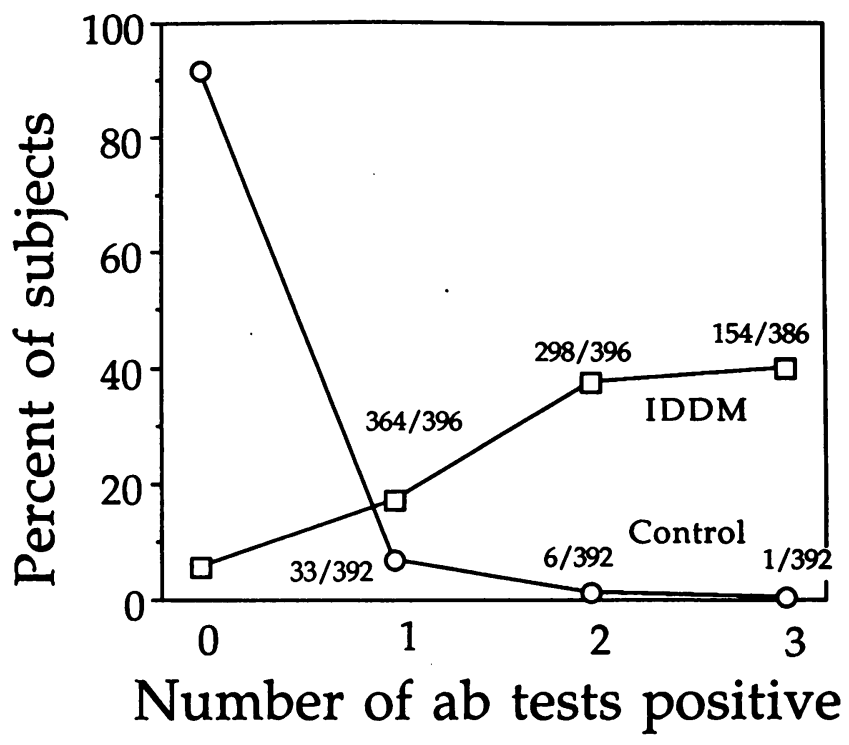

Figure 2. Combinations of qualitative antibody tests (ICA, IAA, GAD65ab) to predict diabetes. Number of diabetic children $(n=386)(\square)$ or matched controls $(n=392)(0)$ with the indicated number of tests positive. Superimposed numbers are cumulative.
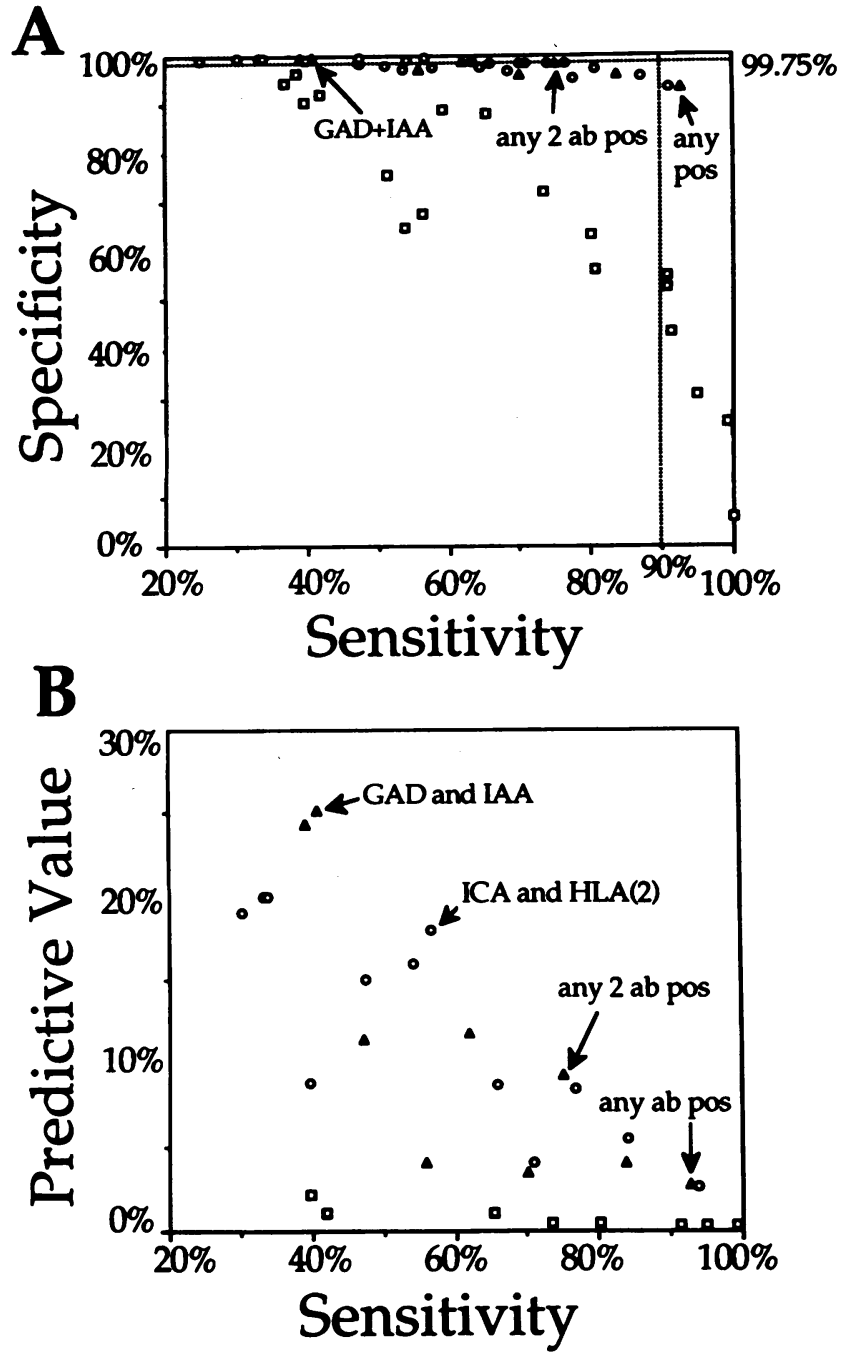

Figure 3. (A) Data from Table I plotted to display sensitivity versus specificity of marker test combinations for childhood diabetes. The vertical dotted line denotes a sensitivity of $90 \%$ potentially useful for screening tests, while the horizontal dotted line represents a specificity of

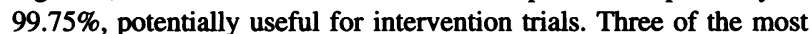
useful antibody test combinations are labeled by arrows. ( $\Lambda$ ) autoantibody tests alone, ( $\square$ ) HLA typing alone, and $(O)$ combined autoantibody and HLA tests. The three circles to the immediate upper left of each solid triangle denote the effect of adding various HLA tests (described in Table I) to a given antibody test. $(B)$ The test combinations from panel A plotted as positive predictive value versus sensitivity, with the four most predictive autoantibody or antibody/HLA combinations indicated by arrows. ( $\triangle$ ) autoantibody tests alone, () HLA typing alone, and $(O)$ combined autoantibody and HLA tests.

the need for multiple substrate pancreata, each with a different sensitivity (31). Tests using recombinant antigens offer greater capacity and standardization. For example, use of 96-well formats is possible (32). Further, antibody detection is sometimes more sensitive, perhaps due to high specific activity of radiolabeled antigen ( $\mathrm{s}$ ) or to detection of epitopes destroyed by cryosectioning and drying. Although it was not possible in the current study to include excess unlabeled recombinant GAD as competitor (as was done for insulin), this should increase specificity and thus predictive value of the GAD65ab test even further (32).

HLA DQ is the best genetic marker of diabetes to date, but 
Table III. HLA DQ Pretesting before Autoantibody Tests in Population Screening for Childhood Diabetes

\begin{tabular}{lcccc}
\hline & $\begin{array}{c}\text { Number } \\
\text { of } \\
\text { alleles } \\
\text { to be } \\
\text { typed }\end{array}$ & $\begin{array}{c}\text { Percent of } \\
\text { true } \\
\text { prediabetics } \\
\text { meeting } \\
\text { typing } \\
\text { criteria }\end{array}$ & $\begin{array}{c}\text { Percent of } \\
\text { population } \\
\text { meeting } \\
\text { typing } \\
\text { criteria }\end{array}$ & $\begin{array}{c}\text { Total } \\
\text { tests } \\
\text { per } \\
\text { capita }\end{array}$ \\
\hline A0301 or A0501 & 2 & 95 & 69 & 7.9 \\
B0302 or B0201 not B0602 & 3 & 91 & 47 & 5.7 \\
A0301 not B0602 & 2 & 80 & 37 & 4.7 \\
B0302 not B301,303,503,602, or 603 & 6 & 66 & 12 & 2.2 \\
B0201 and B0302 & 2 & 39 & 4 & 1.4 \\
& & & &
\end{tabular}

Calculations use sensitivities and specifities from Table I. Tests per capita assumes one HLA typing per lifetime and ten periodic antibody tests on each HLA-high risk subject.

it was of limited predictive benefit in the current, cross-sectional study (Table I) as in other studies. However, an individual's genotype is constant, while antibodies appear at a finite time before onset. Genetic pretesting may identify a cohort whose increased prevalence increases the predictive value of subsequent antibody tests. Increased laboratory automation and relevance to a wide range of autoimmune diseases makes HLA typing at birth attractive for risk stratification. Further, periodic antibody testings as outlined in Table III increase the effective prevalence of IDDM to $0.3 \%$ since the surveillance range increases to age 0-25 years. Predictive value of, for example, the "GAD and IAA" test is increased from $25 \%$ to $~ 33 \%$ from the latter effect alone. Although we do not advocate actual testing at this time, the strategy of Table III is meant to serve as an example of the type of approach that should be considered.

GAD65ab were significantly associated with DQA1 *0501/ DQB1 *0201 (DQ2) in diabetic children, consistent with a previous smaller study (33). IAA were associated with DQA1*0301/DQB1*0302 (DQ8). It is tempting to speculate that these HLA molecules present their respective antigens to T lymphocytes, stimulating B lymphocyte antibody production. However, it should be noted that the above HLA genotypes are not necessary nor sufficient to produce their associated autoantibodies, even in the presence of disease. Fully 49/217 (23\%) patients with DQA1*0501/DQB $1 * 0201$ did not have GAD65ab, and 104/254 (41\%) with DQA1*0301/DQB1*0302 had no IAA. Further, 133/301 (44\%) of persons with GAD65ab were not DQA $1 * 0501 / \mathrm{DQB} 1 * 0201$, and $41 / 191(22 \%)$ of those with IAA were not DQA1 *0301/DQB $1 * 0302$. The latter might be due to multiple distinct antibody epitopes (34), and the former to a predominant TH-1 immune response in some patients (35), but these remain to be confirmed.

In summary, test combinations in addition to GAD65ab, ICA, IAA and HLA genotyping are clearly needed to achieve sufficient predictive value in cross-sectional studies to justify general population immunointervention to prevent IDDM. These may, for example, include autoantibody tests to recombinant antigens not tested here, additional genetic typing, or tests of antigen-specific $\mathrm{T}$ lymphocyte function. If used on antibodypositive subjects to increase predictive values even further, these additional tests would add little to per capita cost, since the overall number of tests is small. Conversely, antibody testing of genetically high risk subjects would also lead to greater efficiencies and higher predictive values. Finally, tailoring of immunotherapy type and toxicity to match test predictive value and stage of prediabetes should be possible.

\section{Acknowledgments}

BHK fibroblasts were from American Type Culture Collection, Bethesda, MD. We thank S. McGrew, S. B. Kaliappan, S. Eastman, and C. Törn for excellent technical assistance, E. Boel, C. Grubin, T. Dyrberg, and D. Foster for help in cloning and expression of recombinant human GAD65, D. Stenger for HLA sequence analyses, and L. Nyström for epidemiological advice. Members of the Swedish Childhood Diabetes Study from all Departments of Pædiatrics in Sweden are: M. Aili, Hamstad; H. Bäckman, Gävle; E. Karlsson, Kalmar; H. Edenwall, Karlskrona; P. O. Elfstrand, Skövde; G. Forsander, Falun; W. B. Grandström, Gällivare; I. Gustavsson, Skellefteå; L.-E. Gustavsson, Östersund; A. Hallberg, Landskrona; R. Hanås, Uddevalla; L. Hellenberg, Nyköping; H. Hellgren, Lidköping; E. Holmberg, Umeå; H. Hörnell, Hudiksvall; C. Johansson, Jönköping; G. Jonsell, Karlstad; G. Jönsson, Sollefteå; K. Kockum, Ystad; U. Lindberg, Växjö; B. Lindblad, Mölndal; A. Lindh, Borås; J. Ludvigsson, Linköping; V. Mazreliez, Visby; U. Myrdal, Västerås; J. Niederud, Helsingborg; K.-O. Nilsson, Malmö; P. G. Petzén, Västervik; G. Samuelsson, Vänersborg; K. Segnestam, Eskilstuna; S. Sjobläd, Lund; S. Sjögren, Örnskölds-Norrköping; U. Stáhle, Ängelholm; J. Tenstam, Sundsvall; B. Thalme, Huddinge; K. Tullus, Danderyd; T. Tuvemo, Uppsala; M. Wallensteen, Stockholm; O. Westphal, Göteborg; and J. Åman, Örebro. Finally, we thank the nearly 1000 Swedish children and their parents for their willing participation.

This study was supported by National Institutes of Health grants DK-41801, DK-42654, DK-02456, and DK-17047, the Howard Hughes Medical Institute (W. A. Hagopian), JDF International (C. B. Sanjeevi and A. E. Karlsen), the Swedish Diabetes Association, the Swedish Medical Research Council, the Malmö Diabetes Association, the Lundström Foundation, the Swedish Insurance Companies Foundation, and the Malmö General Hospital Foundation. GAD-6 hybridomas were from the Developmental Studies Hybridoma Bank, Iowa City, IA, (NIH grant HD-62915).

\section{References}

1. Teruya, M., S. Takei, L. Forrest, A. Grunewald, E. Chan, and M. Charles 1993. Pancreatic islet function in nondiabetic and diabetic BB rats. Diabetes. 42:1310-1317.

2. Buschard, K., C. Brogren, C. Ropke et al. 1986. Antigen expression of the pancreatic $\beta$-cells is dependent on their functional state. APMIS (Acta Pathol. Microbiol. Immunol. Scand.) 96:342-346.

3. Gepts, W. 1981. Islet changes in human diabetes. In Bichemistry, Physiology and Pathology of the Islets of Langerhans. S. J. Cooperstein and D. Watkins, editors. Academic Press, New York. 321-356.

4. Bingley, P., M. Christie, R. Bonfanti, E. Bonifacio, M. Shattock, M. Fonte, G. Botazzo, and E. Gale. 1993. Combined analysis of autoantibodies in prediction of type I (insulin-dependent) diabetes. Diabetologia. 36:A36.

5. Dahlquist, G., L. Blom, and G. Lönnberg. 1991. The Swedish Childhood Diabetes Study - a multivariate analysis of risk determinants for diabetes in different age groups. Diabetologia. 34:757-762.

6. Landin-Olsson, M., J. P. Palmer, A.. Lernmark, L. Blom, G. Sundkvist, L. Nystrom, and G. Dahlquist. 1992. Predictive value of islet cell and insulin autoantibodies for Type I diabetes mellitus in a population based study of newly diagnosed diabetic and matched control children. Diabetologia. 35:1068-1073.

7. Rowe, R., N. Leech, G. Nepom, and D. McCulloch. 1994. High genetic risk for IDDM in the Pacific Northwest-First report from the Washington State diabetes prediction study. Diabetes. 43:87-94.

8. Riley, W. J., N. K. Maclaren, J. Krischer, R. P. Spillar, J. H. Silverstein, D. A. Schatz, S. Schwartz, J. Malone, S. Shah, C. Vadheim, and J. I. Rotter. 1990. A prospective study of the development of diabetes in relatives of patients with insulin-dependent diabetes. N. Engl. J. Med. 323:1167-1172.

9. Baekkeskov, S., T. Dyrberg, and A. Lernmark. 1984. Autoantibodies to a 64-kilodalton islet cell protein precede the onset of spontaneous diabetes in the BB rat. Science (Wash. DC). 224:1348-1350.

10. Eisenbarth, G., R. Jackson, and A. Pugliese. 1992. Insulin Autoimmunity: the rate limiting factor in Pre-type I diabetes. J. Autoimmunity. 5:241-246.

11. Robert, J. J., I. Deschamps, D. Chevenne, M. Roger, A. Mogenet, and C. Boitard. 1991. Relationship between first-phase insulin secretion and age, HLA, 
islet cell antibody status, and development of Type 1 diabetes in 220 juvenile first-degree relatives of diabetic patients. Diabetes Care. 14:718-723.

12. Dahlquist, G., L. Blom, T. Tuvemo, L. Nyström, A. Sandström, and S. Wall. 1989. The Swedish childhood diabetes study-Results from a nine year case register and one year case-referent study indicating that IDDM is associated with both NIDDM and autoimmune disorders. Diabetologia. 32:2-6.

13. Madsen, O., M. Landin-Olsson, G. Bille, G. Sundkvist, Å. Lernmark, G. Dahlquist, and J. Ludvigsson. 1986. A 2-colour immunofluorescence test with a monoclonal human proinsulin antibody improves the ICA assay. Diabetologia. 29:115-118.

14. Palmer, J. P. 1987. Insulin autoantibodies: their role in the pathogenesis of IDDM. Diabetes Metab. Rev. 3:1005-1015.

15. Sanjeevi, C., A. Zeidler, S. Shaw, J. Rotter, G. Nepom, G. Costin, L. Raffel, S. Eastman, I. Kockum, R. Wassmuth, and A. Lernmark. 1993. Analysis of HLA DQ-A1 and -B1 genes in Mexican Americans with IDDM. Tissue Antigens. 42:72-77.

16. Kockum, I., R. Wassmuth, E. Holmberg, B. Michelsen, and A. Lernmark. 1993. HLA-DQ primarily confers protection and HLA-DR susceptibility in IDDM studied in population-based affected families and controls. Am. J. Hum. Genet. 53:150-167.

17. Hagopian, W., A. Karlsen, A. Gottsäter, M. Landin-Olsson, C. Grubin, G. Sundkvist, J. Petersen, E. Boel, T. Dyrberg, and Å. Lernmark. 1993. Quantitative assay using recombinant human islet GAD shows $64 \mathrm{~K}$ ab positively at onset predicts diabetes type. J. Clin. Invest. 91:368-374.

18. Baekkeskov, S., M. Landin-Olsson, J. K. Kristensen, S. Srikanta, G. J. Bruining, T. Mandrup-Poulsen, C. de Beaufort, J. S. Soeldner, G. Eisenbarth, F. Lindgren, G. Sundkvist, and Å. Lernmark. 1987. Antibodies to a $M_{\mathrm{r}} 64,000$ human islet cell antigen precede the clinical onset of IDDM. J. Clin. Invest. 79:926934.

9. Hagopian, W A. Karlsen, J. Petersen, J. Teague, A. Gervassi, J. Jiang W. Fujimoto, and $\AA$. Lernmark. 1993. Regulation of GAD diabetes autoantigen expression in highly purified isolated islets from Macaca Nemestrina. Endocrinology. 132:2674-2681.

20. Schmidli, R., P. Colman, E. Bonifacio, G. Bottazzo, L. Harrison, and participating laboratories. 1994. High level of condordance between assays for GADAb:the first international GADAb workshop. Diabetes. 43:1005-1009.

21. Nyström, L., G. Dahlquist, M. Rewers, and S. Wall. 1990. The Swedish childhood diabetes study: An analysis of the temporal variation in diabetes incidence 1978-1987. Int. J. Epidemiol. 19:141-146.

22. Palmer, J. P. 1993. Predicting IDDM: Use of Humoral Immune Markers. Diabetes Reviews. 1:104-115.
23. Bloom, A. T. M. Hayes, and D. R. Gamble. 1975. British Diabetic Association Survey of Diabetes in Children. Br. Med. J. 3:580.

24. Thivolet, C., M. Tappaz, A. Durand, J. Petersen, A. Stefanutti, P. Chatelain B. Vialettes, W. Scherbaum, and J. Orgiazzi. 1992. GAD autoantibodies are additional predictive markers of IDDM in high risk individuals. Diabetologia. 35:570576.

25. Roll, U., M. Christie, E. Standl, and A. Ziegler. 1994. Associations of anti-GAD antibodies with ICA and IAA in relatives of IDDM patients. Diabetes. 43:154-160.

26. Pietropaolo, M., L. Castano, S. Babu , R. Buelow , Y. Kuo, S. Martin, A Martin, A. Powers, M. Prochazka, and J. Naggert. 1993. Islet cell autoantigen 69 kD (ICA69). Molecular cloning and characterization of a novel diabetes-associated autoantigen. J. Clin. Invest. 92:359-371.

27. Castano, L., E. Russo, L. Zhou, M. Lipes, and G. Eisenbarth. 1991 Identification and cloning of a granule autoantigen (carboxypeptidase- $\mathrm{H}$ ) associated with type I diabetes. J. Clin. Endocrinol. Metab. 73:1197-1201.

28. Hagopian, W., A. Karlsen, E. Boel, T. Dyrberg, R. Rowe, and D. McCulloch. 1992. Autoantibodies to human GAD as an adjunct to ICA and IAA for prediction of IDDM in schoolchildren. Diabetes. 41:95a. (Abstr.)

29. Bottazzo, G. F., A. Florin-Christensen, and D. Doniach. 1974. Islet cell antibodies in IDDM with autoimmune polyendocrine deficiencies. Lancet. ii:1279-1283.

30. Greenbaum, C. J., J. Palmer, S. Nagataki, Y. Yamaguchi, J. Molenaar, W. Van Beers, N. MacLaren, and Å. Lernmark. 1992. Improved specificity of ICA assays in the 4th International IDW Serum Exchange Workshop. Diabetes. 41:1570-1574.

31. Landin-Olsson, M. 1990. Precision of the islet cell antibody assay depends on the pancreas. J. Clin. Lab. Anal. 4:289-294.

32. Petersen, J., K. Hejnaes, A. Moody, A. Karlsen, M. Marshall, M. HoierMadsen, E. Boel, B. Michelsen, and T. Dyrberg. 1994. Detection of GAD65ab in diabetes and other autoimmune diseases using a simple radioligand assay. Diabetes. 43:459-467.

33. Serjeantson, S., J. Court, I. Mackay, B. Matheson, M. Rowley, T. Tuomi, J. Wilson, and P. Zimmet. 1993. HLA-DQ genotypes are associated with autoimmunity to GAD in IDDM patients. Human Immunology. 38:97-104.

34. Richter, W., Y. Shi, and S. Baekkeskov. 1993. Autoreactive epitopes defined by diabetes-associated human monoclonal antibodies are in the middle and C-terminal domains of the smaller form of GAD. Proc. Natl. Acad. Sci. USA 90:2832-2836

35. Harrison, L., M. Honeyman, H. DeAizpurua, R. Schmidli, P. Colman, B. Tait, and D. Cram. 1993. Inverse relationship between humoral and cellular immunity to GAD in subjects at risk of insulin-dependent diabetes. Lancet. 341:13651369. 